\title{
Imagens e experiências nas notícias sobre morte
}

\begin{abstract}
GISLENE DA SILVA
Universidade Federal de Santa Catarina - gislenedasilva@gmail.com Professora do Programa de Pós-Graduação em Jornalismo da Universidade Federal de Santa Catarina (UFSC). Doutora em Ciências Sociais/Antropologia pela Pontifícia Universidade de São Paulo (PUC-SP), com pósdoutorado na Universidade de São Paulo (USP). Bolsista CNPq.
\end{abstract}

\section{Resumo}

Gabriel Shiozawa Coelho

Universidade Federal de Santa Catarina - gabrielscoelho@gmail.com Graduando do Curso de Jornalismo da UFSC/bolsista PIBIC

Este estudo problematiza a morte como acontecimento noticioso e, por conseguinte, as diferentes imagens de morte operadas pela imprensa, tanto no que ela se alimenta do imaginário sóciocultural como no que o reforça. A proposta é sistematizar similaridades e repetições de imagens expostas nos resultados de pesquisa recente realizada por um grupo de professores que investigou a morte como acontecimento noticioso por um período específico da cobertura da mídia e com base em uma diversidade de métodos e materiais jornalísticos.

Palavras-chave: Jornalismo. Notícia.Imaginário. Morte.

\begin{abstract}
This study discusses death as newsworthy event and therefore the different images of death operated by the press, both in that it feeds the socio-cultural imaginary as in the reinforcing it. The proposal is to systematize similarities and repetitions of images displayed on the results of recent research conducted by a group of professors who investigated the death as a newsworthy event for a specific period of time of the news coverage, with basis in a diversity of methods and journalist materials.
\end{abstract}

Keywords: Journalism. News. Imaginary. Death.

\section{Artigo recebido em 10/09/2013 \\ Aprovado em 01/11/2013}


Estudos em Jornalismo e Mídia - Vol. 10 № 2 - Julho a Dezembro de 2013

nteressa-nos aqui neste estudo a morte como acontecimento noticioso e, por
conseguinte, as diferentes imagens de morte operadas pela imprensa, tanto no que ela
se alimenta do imaginário sociocultural como no que o reforça. Para Bird e Dardene os relatos jornalísticos proporcionam às pessoas mais do que fatos e informações objetivas - apresentam "um esquema para perspectivarem o mundo e viverem a sua vida" (BIRD; DARDENE, 1993, p. 266). E se as matérias jornalísticas se inserem rotineiramente nas nossas vidas, mais ainda nos afeta quando elas tratam de mortes. Avaliamos que são muitas as notícias sobre morte porque a morte noticiada pode ser considerada o acontecimento noticioso primordial, a partir do qual grandes manchetes e coberturas ganham vida (SILVA, G, 2012, p. 472).

Por isso, partimos de um pressuposto e de uma indagação: “A morte, só podemos acessá-la, experimentá-la via o outro. Se a imprensa se constitui no e pelo relato da experiência do outro, o que, então, o jornalismo faz ou deixa de fazer com a experiência do leitor/telespectador diante da morte noticiada?" (SILVA, G, 2012, p. 467). E, assim, trabalhamos com o seguinte entendimento: "se aprendemos, além de nossas próprias experiências, com as experiências dos outros, e se a narrativa jornalística é, por excelência, referencial e fática, a noção de experiência teria força como operador da compreensão do lugar que tais imagens de morte ocupam na imaginação pública. (SILVA, G; VOGEL, D., 2012, p. 181).

As coberturas jornalísticas sobre os acontecimentos de morte se diferenciam para além da linha editorial e público, dependendo de quem morre ou de quantos morrem ou como se morre. Conforme inventariamos em outro texto (SILVA, G, 2012, p. 462), vários pesquisadores escreveram a respeito da relação mídia-morte. No estudo de Issler sobre anúncios fúnebres nos jornais, a morte, como qualquer outro fato, não tem valor jornalístico nela mesma. "Quem atribui valor à realidade, seja jornalístico, acadêmico, jurídico ou artístico é qualquer sujeito que a considere, que a contemple. Assim, é prerrogativa do 
Estudos em Jornalismo e Mídia - Vol. $10 \mathrm{~N}^{\circ} 2$ - Julho a Dezembro de 2013

profissional da informação definir o valor da morte.” Ao entrevistar jornalistas sobre qual o valor jornalístico da morte, o pesquisador obteve nas sessenta respostas uma convergência, de certo modo óbvia: "a morte é pauta em função de quem morre e de como morre" (ISSLER, 2004). Em se tratando de grandes mortes na mídia, Mouillaud identifica os mortos banais e mortos exclusivos, os crônicos ou acidentais, os privados ou públicos, os mortos em obituários, os mortos dos conflitos, das guerras e das revoluções, o grande morto válido por seu próprio nome versus aqueles anônimos mortos em acidentes, tomados por sua grandeza numérica (MOUILLAUD, 2002). Para Rodrigues (2010), "nos vários sistemas culturais de classificação da morte, a convivência do insólito e do comum, do acidental e do determinado, do previsível e do surpreendente inspira-se na própria absurdidade do drama final da existência humana". Inserimos todas essas considerações na perspectiva de que as imagens em circulação se organizam em figurações específicas.

A reverência ao morto célebre, o lamento pelos mortos de catástrofes ambientais, a indignação pelas mortes políticas ou o temor da morte violenta - na ação da mídia, tais imagens podem ser cristalizadas, deslocadas ou apagadas pela cobertura noticiosa, criando figurações específicas que, por sua vez, são acionadas pelos sujeitos-leitores a partir de memórias e repertórios que são sempre em alguma medida singulares e, em alguma outra medida, social e culturalmente compartilhados, comuns. E se os vínculos temporais traçados na relação acontecimentonotícia surgem à primeira visada como diacrônicos (a cada dia sua morte, em cada edição sua escolha para chamada de capa), essa homogeneidade temporal do presente se esgarça toda vez que esse notícia-acontecimento é de novo e renovadamente inscrito na grande rede heterotópica dos significados culturais. (SILVA, G; VOGEL, D., 2012, p. 178).

Também de acordo com o que observamos antes (SILVA, G, 2012, p. 467), as narrativas sobre a morte e os mortos podem cambiar os sentidos de próximo e distante. $\mathrm{O}$ morto familiar, quando midiatizado e reforçado em sua imagem pública, fica distante para os próximos a ele; o morto distante, por sua vez, passa a ser chorado pela multidão nos acenos e nas filas de despedida como o mais íntimo parente ou amigo. $\mathrm{O}$ imaginário 
Estudos em Jornalismo e Mídia - Vol. $10 \mathrm{~N}^{\circ} 2$ - Julho a Dezembro de 2013

místico/mágico/religioso participa da conformação das concepções morte, de caráter móvel e em trânsito, em constante adaptação, por influência da bagagem cultural, da família, da etnia, das condições socioeconômicas, da mídia, do jornalismo. Logo, as imagens de morte formam um conjunto de forças em tensão, em mudança contínua, localizadas nos terrenos abertos e instáveis dos imaginários culturais. A um só tempo, tais imagens são míticas, imaginárias, simbólicas, políticas, ideológicas, sem clara distinção. Os acontecimentos de morte, mesmo em sua variedade de manifestação, não escapam ao apelo da emoção diante do enigma do morrer ou diante do esforço em compreender a morte, tanto para negá-la ou aceitá-la. Na abordagem antropológica de Durand (1997), o imaginário manifesta-se num vaivém entre as raízes inatas da representação do sapiens e as várias interpelações do meio social. Dentro de uma mesma sociedade, de uma mesma cultura, vamos nos deparar com diferentes conjuntos interpretativos do fenômeno morte.

Pesquisa recente, realizada por um grupo de professores da área da Comunicação/Jornalismo, revela muito dessas diferentes interpretações quando problematiza, com grande diversidade de objetos empíricos, a morte como acontecimento noticioso $^{1}$. Trata-se do conjunto de textos que compõem o livro Jornalismo $e$ acontecimento: diante da morte. Nosso objetivo, neste momento, é percorrer todos esses textos e seus resultados a partir de métodos e materiais jornalísticos diversos, para observar similaridades e repetições no tratamento do acontecimento jornalístico-morte. São estes os textos que analisamos: TEXTO 1 Lições de morte nos jornais, de Paulo Bernardo Ferreira Vaz, investiga mortes que apareceram em jornais de referência e populares, numa “miscelânea jornalística nacional-local direcionada para públicos diferenciados”, simulando a captação de notícias no dia-a-dia, da forma como o leitor as encontraria. TEXTO 2

1 Jornalismo e acontecimento: diante da morte do grupo "PROCAD - TECER: Jornalismo e Acontecimento Equipe: Christa Berger (coord) / Beatriz Alcaraz Marocco / Ronaldo Cesar Henn (UNISINOS); Gislene da Silva / Eduardo Meditsch / Daisi Vogel (UFSC); Marcia Benetti Machado / Flávio Antônio Camargo Porcello / Virgínia Pradelina da Silveira Fonseca (UFRGS); Paulo Bernardo Ferreira Vaz / Elton Antunes / Bruno Souza Leal (UFMG). Financiador: CAPES. 
Estudos em Jornalismo e Mídia - Vol. $10 \mathrm{~N}^{\circ} 2$ - Julho a Dezembro de 2013

Notícias depois da morte: visibilidades e ausências no jornalismo, de Elton Antunes, estuda a morte nos crimes passionais: episódios envoltos em mistérios, dúvidas e investigações, que ganham seguimento para além de um evento cronologicamente marcado. TEXTO 3 A cotidianidade do morrer na vida noticiosa: ambiguidades de um acontecimento jornalístico diário, de Frederico de Melo Brandão Tavares, acompanha o processo de midiatização do acontecimento-morte e como se comporta a imprensa em relação ao morrer cotidiano. TEXTO 4 O realismo em questão: reflexões a partir da morte como acontecimento nas narrativas jornalísticas, de Bruno Souza Leal, trata da ressignificação da morte e sustenta a tese de que o morrer é o limite do noticiável, não alcançado pelo jornalismo. TEXTO 5 Os mortos vivem no twitter: outras camadas da morte como acontecimento, de Ronaldo Henn, demonstra, a partir dos perfis no twitter de Caio F. Abreu, Clarice Linspector e Nair Bello, geradores e armazenadores de memórias, como a morte passa a integrar as lógicas que regem as mercadorias simbólicas, para além de sua acontecimentalização. TEXTO 6 Consentimento para matar: o contexto sociocultural como substrato do acontecimento na cobertura, de Eduardo Meditsch, discute como o contexto sociocultural do nacionalismo norte-americano, após o 11 de setembro, desencoraja uma postura independente na cobertura dos assuntos militares do país, especificamente das guerras e seus mortos. TEXTO 7 A apropriação discursiva da morte pelo leitor, de Marcia Benetti, analisa como o leitor (internauta) se apropria do discurso de morte, a partir das notícias do naufrágio do navio Costa Concórdia, na Itália. TEXTO 8 Imagens de morte na primeira página, de Daisi Vogel e Gislene Silva, estuda a figuração da morte no imaginário dos que produzem e consomem notícias, observando capas de jornais. TEXTO 9 A morte iminente nos fait divers, de Beatriz Marocco, trata da constituição da morte como acontecimento nos fait divers, que desafiam a objetividade jornalística. TEXTO 10 Sensacionalismo, espetacularização e visibilidade: as notícias sobre as mortes de Chico Anysio e Millôr Fernandes nos telejornais, de Flávio Porcello, 
Estudos em Jornalismo e Mídia - Vol. $10 \mathrm{~N}^{\circ} 2$ - Julho a Dezembro de 2013

dedica-se às mudanças na estética nos telejornais na cobertura de mortes de figuras públicas. TEXTO 11 O gênero que mata: memória de punição, de Christa Berger, traz questões de gênero e valoração, observando o acontecimento jornalístico em relação à memória da punição.

$\mathrm{Na}$ leitura de todo esse material, identificamos ocorrências que se repetem na busca pelo entendimento da morte como acontecimento noticioso e as organizamos em 05 conjuntos de imagens-experiências: (1) ritualização, tentativa de compreensão e reordenação; (2) a morte do outro, alivio, não aconteceu comigo; (3) morte próxima do meu cotidiano; (4) extraordinárias, mas comuns e (5) morte distante, ausente.

\section{Imagens e experiências}

Passamos agora a sistematizar os conteúdos desses conjuntos de imagensexperiências, na forma de fragmentos dos textos do corpus deste estudo, ou seja, dos capítulos do livro Jornalismo e acontecimento: diante da morte.

\section{Ritualização, tentativa de compreensão e reordenação}

A morte aparece no meio jornalístico como uma forma de tentar entender a ruptura com vida, esse abismo na compreensão humana. Nos fragmentos de textos a seguir, percebemos formas de compreender e suportar a situação, justificar o ocorrido e julgar possíveis culpados tentando, desta forma, reordenar algo que saiu repentinamente do lugar. A morte como acontecimento aparece, aqui, como uma espécie de lição de vida.

Paulo Bernardo Ferreira Vaz introduz o tema da compreensão do acontecimento morte com uma citação de Freud "Se quiseres suportar a vida, prepara-te para a morte" (Texto 1, p. 21), retirada de um texto que diz que ninguém na verdade crê na própria morte e que há a tendência de excluirmos a morte de nossos projetos de vida (Freud, 2006 p. 299 e p. 301). Seguindo esta percepção, Vaz analisa a morte no jornalismo como uma tentativa 
Estudos em Jornalismo e Mídia - Vol. $10 \mathrm{~N}^{\circ} 2$ - Julho a Dezembro de 2013

(não necessariamente consciente) de estabelecer no leitor uma compreensão e aceitação: “(...) que preparação para a morte seria esta que deve ensinar aos homens modernos leitores de jornais e receptores de todas as mídias - a 'suportar a vida'? A presença constante da morte nos jornais seria uma lição diária passada pelos veículos aos seus leitores habituais ou esporádicos?" (Texto 1, p. 21). No texto, também aparecem aspectos que mostram a notícia sobre a morte como uma ritualização do acontecimento, para fins de compreensão e reordenação, uma "lembrança" do que vai acontecer com todos nós, acontecimento inevitável: "A mídia parece falar incessantemente da morte como se mantivesse diuturnamente acesa uma lâmpada votiva de memento mori no altar de cada leitor bem vivente" (Texto 1, p. 23). Porém, o autor entenda isso como uma "inaceitação do aniquilamento", a partir do momento em que o leitor consome, dia após outro, notícias parecidas sobre o tema.

Márcia Benetti, ao tratar das apropriações discursivas da morte pelos leitores, fala dos aspectos simbólicos que ela carrega: "O conteúdo simbólico da morte é tão pesado e fundo, que exige ritualizações (Ariès, 2003) para que seja suportado” (Texto 7, p. 153). A partir daí, elenca os aspectos pelos quais o jornalismo tenta tornar o acontecimento mais compreensível para o público: "A morte é objetivada e qualificada no jornalismo pela narrativa dos detalhes que lhe dão ancoragem ao real, pelos textos e infográficos de contextualização e pelas explicações oferecidas pelos especialistas. Mas o fato de ser objetivada não lhe retira o poder simbólico" (Texto 7, p. 154). É a partir da ancoragem no real, através dos textos e explicações, que se tenta compreender a morte, o que Benetti diz acontecer primeiramente com aspectos do acontecimento que permitem ao leitor justificar os fatos e julgar os envolvidos: "O primeiro movimento é o da responsabilização. O leitor pergunta imediatamente: quem é o culpado? Entender quem é o responsável é fundamental para reordenar, no mundo, o que repentinamente saiu do lugar" (Texto 7, p. 163). 
Estudos em Jornalismo e Mídia - Vol. $10 \mathrm{~N}^{\circ} 2$ - Julho a Dezembro de 2013

Seguindo esta linha de "justificar e julgar", Daisi Vogel e Gislene Silva tratam dos casos de morte que aparecem na primeira página: "Esses dois conjuntos de chamadas de capas para notícias de mortes individuais possuem certa mensagem-motivação convergente, a de rastrearem a responsabilidade por mortes de um ou de outro modo provocadas" (Texto 8, p. 176). A tentativa de compreensão da morte aparece no texto das autoras com enfoque no destaque dado pelos jornais para matérias que afetam emocionalmente os leitores: "Os acontecimentos de morte, mesmo em sua variedade de manifestação nas chamadas de capa, não escapam ao apelo da emoção diante do enigma do morrer ou diante do esforço em compreender a morte, seja ao negar ou ao aceitar. [...] No caso específico da morte, o que se faz notório nessa operação de montagem [da produção jornalística] é quais mortes ganham um estatuto (logo, uma dimensão) de visibilidade e compartilhamento e quais ingredientes de carga afetiva mobilizam profissionais e consumidores da notícia” (Texto 8, p. 182). As autoras também trabalham com a compreensão da morte a partir do outro e do jornalismo: “A morte própria é a experiência que não podemos experimentar e contá-la e aprender com ela. Podemos até ter aproximações. [...] A morte, só podemos acessá-la, experimentá-la pelo outro. Ora, o jornalismo se constitui basicamente no e pelo relato da experiência do outro, e o faz organizando, montando conjuntos de imagens" (Texto 8, p. 182).

Christa Berger, tratando das notícias de mortes de mulheres, pontua a importância das narrativas sobre os acontecimentos, mais especificamente das jornalísticas, para suportar e compreender as situações de mortes, embora estas não impeçam que o fato volte a acontecer: “[...] sabedoria de Isak Dinesen, para quem todos os sofrimentos podem ser suportados se você os puser numa história ou contar uma história sobre eles. [...] As narrativas que salvam, curam, esclarecem, fazem suportar, oferecem, também, modelos e matrizes para dar sentido ao que volta a acontecer" (Texto 11, p. 221). 
Estudos em Jornalismo e Mídia - Vol. $10 \mathrm{~N}^{\circ} 2$ - Julho a Dezembro de 2013

\section{A morte do outro, alívio, não aconteceu comigo}

Gislene Silva e Daisi Vogel trouxeram a ideia da experiência de morte a partir do outro no jornalismo, visto que "a morte própria é a experiência que não podemos experimentar e contá-la e aprender com ela" (Texto 8, p. 182). As autoras dizem que só é possível conseguir aproximações, a partir do relato de outros. Os fragmentos a seguir mostram a ideia de que, a partir desses relatos da morte do outro, o leitor/telespectador se sentiria aliviado porque aquele que morreu na notícia não é ele mesmo. A morte é do outro, não aconteceu comigo.

Para Paulo Bernardo Vaz a morte está sempre presente "[...] para ser divulgada, vista, lida e reconhecida pela consciência de todos os leitores. Leitor que "compõe" o acontecimento ao se dar conta das narrativas verbo-visuais, talvez respirando aliviadamente ao tomar consciência que se trata morte de outrem" (Texto 1, p. 22). Recorre a Michel de Certeau, em A invenção do cotidiano: artes de fazer: "Pela representação, exorcizo a morte, colocado no vizinho, relegada num momento do qual postulo o que não é meu. Protejo o meu lugar. O moribundo de que falo é obsceno, se não sou eu" (Texto 1, p. 46). E, aproximando o alívio perante a morte do outro e a tentativa de negação da morte própria, pensando a grande quantidade de matérias jornalísticas que tratam da morte ou de mortes, conclui: "[...] a imprensa nos fornece farto material com o qual podemos proteger o nosso próprio lugar. Eles, de quem falam, não somos nós (Sontag, 2007). Eles serão sempre os outros, não eu, leitor. O lugar que queremos demarcar é o de sobre/viventes nesta luta pela vida" (Texto 1, p. 46 - Sontag em Olhando o sofrimento dos outros).

O alívio pelo qual o leitor passa ao ver na morte do outro uma morte "não sua" é colocado por Beatriz Marocco como um poder de atração nos produtos jornalísticos: "Tais notícias, em que a violência é protagonista, dão conta dos aspectos inexplicáveis da nossa existência e retiram o seu poder de atração do fato de proporcionarem acesso a fenômenos perturbadores e a expressão de quase alívio, "ah, poderia ter acontecido comigo", a que as 
Estudos em Jornalismo e Mídia - Vol. 10 № 2 - Julho a Dezembro de 2013

mídias respondem automaticamente com uma norma a ser seguida da distância segura, em que nos encontramos, porque poderíamos estar, mas não estamos diretamente envolvidos nos acontecimentos" (Texto 9, p. 187). Essa "distância segura" passa um quê de mistério, de coisas não ditas dada a natureza do fato relatado, e levando em conta o que o leitor deseja ou não saber sobre cada assunto. A autora argumenta que essa distância não se aplica a quando o tema tratado não ameaça a audiência com a morte: “O mesmo não se dá, porém, em relação ao noticiário sobre a política e a economia, domínios nos quais a nossa própria existência está em jogo e em relação aos quais os leitores não apreciam o mistério" (Texto 9, p. 187).

\section{Morte próxima do meu cotidiano}

Há os "morreres possíveis", mortes que poderiam acontecer com qualquer um e são, portanto, próximas - ou aproximadas - do contexto do leitor/telespectador. Alguns dos resultados do livro analisado remetem a mortes ocorridas em circunstâncias comuns no cotidiano dos leitores e que, portanto, poderiam acontecer com eles. Esta possibilidade geraria interesse e temor.

Elton Antunes coloca essa aproximação como uma estratégia editorial para que os leitores se engajem emocionalmente com a notícia “[...] um local em que já se foi, um trem que já se utilizou etc. [...]" (Texto 2, p. 60), mas que acontece conjuntamente com um processo de estranhamento e objetivação para que a audiência possa se distanciar o suficiente para consumir o relato do acontecimento. Continua: "Todas mortes possíveis a qualquer um, disponíveis a todos, cujas histórias particulares indicam os pormenores da situação, um mapa dos perigos do mundo. São mortes próximas ou, mais propriamente, aproximadas, com estratégias que permitem zonas de contato e interseção com a vida de todo dia" (Texto 2, p. 62). O autor conclui que a forma com que é percebida a morte como 
Estudos em Jornalismo e Mídia - Vol. $10 \mathrm{~N}^{\circ} 2$ - Julho a Dezembro de 2013

notícia também define o objetivo ou enfoque principal da matéria: "Assim, onde parece ser uma morte singularizada, a notícia é sobre um 'morrer possível’” (Texto 2, p. 62).

Que todos estamos sujeitos às situações noticiadas de morte parece ser o aviso de várias matérias jornalísticas. Gislene Silva e Daisi Vogel observam a questão quando traçam os contrastes que fazem com que uma morte seja noticiável: "[...] uma jovem que morre num brinquedo que devia diverti-la, uma mãe que assiste ao brinquedo que mata, a conversão da experiência em exemplo, "pode acontecer com você"” (Texto 8, p. 175). Beatriz Marocco vai além, ao colocar esse aviso como uma possível estratégia de controle social: “(...) a mensagem que evoca o medo de circular no espaço urbano e guarda uma estratégia de controle social sob o véu da ficção jornalística, ou seja, o que aconteceu com o menino pode acontecer com qualquer um de nós, ou com nossos filhos” (Texto 9, p. 194).

As aproximações feitas entre o conteúdo da notícia e o cotidiano da audiência, embora não necessariamente torne os dois "mundos" mais próximos, não é feita de forma desinteressada. Márcia Benetti mostra como os leitores/telespectadores são afetados pela proximidade e possibilidade de se imaginar no lugar daquele que morreu: "O leitor que escreve no espaço dos comentários se apropria do discurso jornalístico e constrói, por sua vez, um novo discurso sobre o que leu. Algumas emoções são desencadeadas pelo relato de uma tragédia, especialmente surpresa, tristeza e medo. Elas derivam da capacidade de sentir empatia em relação ao outro e de conseguir se imaginar no lugar deste outro" (Texto 7, p. $160)$.

\section{Extraordinária, mas comum}

Os meios jornalísticos criam um paradoxo por envolver os acontecimentos de morte em uma aura de extraordinário, ao mesmo tempo em que inserem essas notícias numa lógica de periodicidade. A repetição transforma as notícias de morte em algo 
Estudos em Jornalismo e Mídia - Vol. $10 \mathrm{~N}^{\circ} 2$ - Julho a Dezembro de 2013

extremamente comum. Embora a morte seja a ruptura da ordem da vida, não é a ruptura da ordem cotidiana do jornalismo, uma vez que aparece cotidianamente nos jornais.

Esse fenômeno foi observado por diversas vezes nas pesquisas do livro aqui analisado. Na parte da pesquisa realizada por Christa Berger, a autora sugere que, para aparecerem nos jornais, as mortes necessitam, cada uma delas, de uma característica que lhes destaquem. "Se a morte é o acontecimento previsto na vida de cada um de nós, tornouse um acontecimento paradigmático do jornalismo por permitir observar o ponto de inflexão que um acontecimento deve conter para se tornar notícia, neste caso, o que a morte, quando não pela proeminência do morto, deve carregar de inusitado, anormal, improvável para ingressar nas páginas dos jornais” (texto 11, p. 222). Frederico de Melo Brandão Tavares, no seu texto, pontua de forma clara: "Sua presença [a da morte] rotineira, entretanto, quando captada pela imprensa, dá à dimensão de sua vivência um outro caráter. A morte cotidiana que abunda as páginas do jornal é, ela mesma, uma morte comum, que assim se torna, pela maneira como o jornal a faz, repetitivamente, ordinária” (Texto 3, p. 75). Logo adiante, Tavares utiliza uma expressão bastante significativa para demonstrar esse paradoxo característico da morte nos jornais: excepcionalidades altamente ordinárias. $\mathrm{Na}$ experiência jornalística dos e sobre os acontecimentos, o "caráter de ruptura aparece semanticamente expresso, mas encontra-se configurado pela prática narrativa que os "normaliza"' (Texto 3, p. 75). Ambivalência análoga à anotada por Marcia Benetti em seu texto: "O jornalismo vive um paradoxo: conta uma novidade e mostra que ela não é tão nova assim" (Texto 7, p.153).

Da mesma forma, Daisi Vogel e Gislene Silva analisam o vínculo temporal na relação acontecimento-notícia, percebendo que mesmo que surjam "à primeira vista como diacrônicos (a cada dia sua morte, em cada edição sua escolha para chamada de capa), essa homogeneidade temporal do presente se esgarça toda vez que esse acontecimento-notícia é 
Estudos em Jornalismo e Mídia - Vol. 10 № 2 - Julho a Dezembro de 2013

de novo e renovadamente inscrito na grande rede heterotópica dos significados culturais" (Texto 8, p. 179).

Embora também trate da questão temporal e da repetição das mortes nos jornais, Bruno Souza Leal complementa com outra abordagem. Para o autor, o fato de a imprensa exibir cotidianamente "mortes anônimas" tem por efeito torná-las invisíveis, ao invés de expô-las. "A realidade fixada pelo gesto realista destina-se à desaparição; o esforço de ver, de registrar, de fixar, implica também não ver, não narrar, deixar passar” (Texto 4, p. 101). O morrer do dia-a-dia, por seu caráter repetitivo e comum, banaliza-se e acaba caminhando para a insensibilidade. "Aqui, o realismo das notícias parece atingir seu paroxismo: a informação é direta, rápida, fugaz como uma realidade cotidiana em que mortes anônimas não cessam de ocorrer e não comovem, não deslocam, simplesmente 'acontecem"” (Texto 4, p. 101).

\section{Morte distante, ausente}

A morte aparece como não entendida, não explicada, tangenciada e de "corpo ausente". Talvez pela dificuldade em ser retratada, aprofundada, enfrentada, a morte se esconde nas próprias notícias de morte. A morte, ela mesma como um grande acontecimento abstrato, se esconde.

"O homem moderno, que identificamos nos leitores de jornais e receptores de todas as mídias contemporâneas, dá-se conta das lições que talvez não o propriamente o preparem para a morte, mas ao colocá-lo no íntimo e constante contato com ela, parece da morte mesmo afastá-lo. [...] Edgar Morin alerta que 'a mesma consciência nega e reconhece a morte: nega-a como aniquilamento, reconhece-a como acontecimento"” (Texto 1, p. 22), observa Paulo Bernardo Ferreira Vaz sobre a dificuldade de encarar a morte em si mesma. Esta dificuldade resulta num fenômeno descrito por diversos dos autores do livro analisado: a dificuldade em retratar a morte e, além da incapacidade, a recusa. A morte em si não é 
Estudos em Jornalismo e Mídia - Vol. $10 \mathrm{~N}^{\circ} 2$ - Julho a Dezembro de 2013

mostrada - são utilizados recursos estéticos, redacionais, números, fotos do morto iminente, mas a morte não aparece explicitada. Resume Christa Berger: "Enquanto o contexto do acontecimento pode ser recuperado com precisão, o momento da morte é um segredo enterrado com as vítimas" (Texto 11, p. 238).

De lugar semelhante parte Bruno Souza Leal quando questiona “[...] como se dá essa escrita jornalística que evita a morte? Que realismos, melodramas - ou outras tradições estéticas - são atualizados nesses jogos delicados e multifacetados entre presença e ausência, entre lembrar e esquecer?” (Texto 4, p. 92). O próprio autor apresenta, ao menos parcialmente, uma resposta. "Pequenos fatos, que não duram mais que poucas linhas. Pequenas e genéricas mortes. Notas curtas: acidentes, fatalidades, crimes passionais. Muito pouco é dito, muito pouco se sabe. Da morte e dos mortos, nada mais que circunstâncias. Afinal, quem morreu? Que vida é essa que cessou? (Texto 4, p. 101)”.

São exibidas as circunstâncias, os comos, os porquês, os nomes e os números. Nunca a morte - nem mesmo nas fotografias. Com essa percepção corrobora Beatriz Marocco: “A imagem, desde outro ponto de observação, evitou o corpo do morto e um detalhe qualquer que poderia torná-lo presença: apontou para a morte iminente (que já passou)" (Texto 9, p. 193). Um pouco à frente, Marocco retoma o conceito da morte iminente: "O que se vê [nas imagens] é um fenômeno que excede a estrutura da notícia: nelas existe uma quase morte: as fotografias apresentam o domínio da morte iminente, ou seja, de um momento anterior ou imediatamente posterior à morte, que se abre às especulações e emoções do leitor e que será mais lembrado do que os textos que acompanham, descrevem e esclarecem uma história complexa (Zelizer, 2010)” (Texto 9, p. 200).

A esse mesmo resultado chegou Elton Antunes: "Durante os dias acompanhados na editoria não houve qualquer imagem fotográfica com, por exemplo, corpos, corroborando a tese de Hanusch (2008) de que a representação visual da morte se faz ausente do noticiário, 
Estudos em Jornalismo e Mídia - Vol. $10 \mathrm{~N}^{\circ} 2$ - Julho a Dezembro de 2013

em particular nos chamados qualitypapers" (Texto 2, p. 58). O autor ainda chama a atenção para outra questão: a ausência da morte causada pela impessoalidade dos números. “Impossível não ver números, improvável figurar a morte. Ao longo das duas semanas de atenção ao conjunto da mídia informativa em nenhum momento a quantidade de mortos havia se imposto como questão ou ponto de atenção, ainda que os números sempre fossem apresentados em profusão e os paralelos feitos ('já são mais de...', 'a maior tragédia desde...'). Aos borbotões a morte é uma ausência" (Texto 2, p. 59). Para Antunes, a falta de imagens e o uso de números decorrem de uma impossibilidade de representar a morte de fato. "Parecem poucos os momentos, menores os gestos em que a morte se apresenta como parte, como comum, como pertença ao cotidiano para as audiências, como uma figuração possível" (Texto 2, p. 67). "Mas a aproximação às mortes no noticiário não indicam exatamente, todavia, proximidade com a morte. A mídia informativa fala muito da morte, o que não significa que as audiências estejam mais próximas a ela” (Texto 2, p. 67). Assim, apesar de notícias sobre pessoas que morreram aparecerem todos os dias nas páginas dos jornais, haveria uma distância enorme entre os leitores e as mortes.

Leal também sinaliza para conclusão semelhante, mas que diverge em um ponto: para o autor, a distância não é apenas entre morte e audiência - morte e jornalismo estão distantes. "A morte, ao contrário do que se pensa, portanto, seria exatamente o limite do noticiável, aquilo que o jornalismo não alcança e o qual buscaria evitar. A noticiabilidade da morte, menos que inevitável, se daria quando ela pudesse ser interpretada e organizada narrativamente de modo a tornar possível a produção de relatos consumíveis, de diferentes maneiras, por parte dos leitores, internautas, ouvintes, telespectadores" (Texto 4, p. 92). Ao discutir a morte no jornalismo, o autor afirma seu caráter distanciado e de "corpo ausente": "A presença da morte no jornalismo, nessa perspectiva, seria como uma espécie de sombra ou fantasma: algo insidioso, que busca a visibilidade, que desafia o olhar cuja atenção dedica-se a outras presenças. Isso porque a morte, ainda que mencionada nas histórias, 
Estudos em Jornalismo e Mídia - Vol. $10 \mathrm{~N}^{\circ} 2$ - Julho a Dezembro de 2013

desafiaria, de modo insuperável, a compreensão humana, constituindo-se, como diz Alfred Schutz (2008a e b), ao mesmo tempo em nossa maior certeza e base de uma ansiedade fundamental: sabemos que vamos morrer, que caminhamos para a morte, mas evitamos pensar nisso, criamos recursos que adiam esse confronto e nos desviam dessa certeza" (Texto 4, p. 92). Conclui Leal que o fato de se exibir muitas mortes, sem exibir a morte em si, cria-se um efeito contraditório, um desvio: "Ao falar sobre as mortes que eclodem e fazem parte do nosso cotidiano social, as histórias que o jornalismo conta como que nos desviam o olhar em direção à vida, nos fazendo ao mesmo tempo esquecer que morremos e nos lembrando das circunstâncias, alegrias, misérias e contradições do viver” (Texto 4, p. 92).

\section{Comentário final}

Reafirmamos que a confrontação com os acontecimentos é, pois, um componente essencial da organização da experiência. Essa confrontação apresentaria duas faces. De um lado, tentaríamos domesticar os acontecimentos, reduzindo a descontinuidade que comportam. De outro, os acontecimentos trariam até nós sua força como esclarecimento, revelando uma situação inédita, insuspeitada, e seu caráter problemático (Quéré, 2010, p. 35). Por isso, no estudo da morte como acontecimento noticioso, levamos em conta que os critérios que orientam as escolhas de notícias de morte extrapolam decisões profissionais, implicando memórias, valores e sentimentos, tanto do jornalista como dos consumidores de notícias. Pois, uma vez que o jornalismo é resultante de movimentos múltiplos entre diferentes sujeitos (repórteres, fontes e leitores/telespectadores), com circulação constante de imagens entre tais atores sociais, pode-se afirmar que há compartilhamento de experiência entre eles. Na relação entre morte e jornalismo, importa o aspecto coletivo do acontecimento, a manifestação social deste imaginário, "uma vez que o fenômeno da comunicação noticiosa é de natureza igualmente social e coletiva" (SILVA, 2010, p. 245). 
Estudos em Jornalismo e Mídia - Vol. $10 \mathrm{~N}^{\circ} 2$ - Julho a Dezembro de 2013

ISSNe 1984-6924

DOI: http://dx.doi.org//0.5007/I984-6924.2013v10n2p495

Por isso, esse conjunto de imagens de morte manifestas em acontecimentos noticiosos diz das experiências de sujeitos sociais, e diz também dos modos como o jornalismo opera nessa dinâmica. 
Estudos em Jornalismo e Mídia - Vol. 10 NN$^{\circ} 2$ - Julho a Dezembro de 2013

\section{Referências}

BIRD, Elizabeth; DARDENNE, Robert (1993). Mito, registro e histórias: explorando as qualidades narrativas das notícias. In: TRAQUINA, Nelson. Jornalismo: questões, teorias e estórias. Lisboa: Vega, 1993. pp. 263277.

DURAND, Gilbert. As estruturas antropológicas do imaginário; introdução à arquetipologia geral. São Paulo: Martins Fontes, 1997.

FREUD, Sigmund. Reflexões para os tempos de guerra e morte (1915). In:__. Obras psicológicas completas de Sigmund Freud: edição standard brasileira. Rio de Janeiro: Imago, 2006. Vol. XIV.

ISSLER, Bernardo. "A morte como notícia ou anúncio". XIII Encontro Anual da Associação Nacional dos Programas de Pós-Graduação em Comunicação, 2004, UMESP, São Bernardo do Campo, SP. Anais eletrônicos.

MOUILLAUD, Maurice. As grandes mortes na mídia. In: PORTO, Sergio Dayrell (org.). O jornal: da forma ao sentido. Brasília: Editora da UnB, 2002.

QUÉRÉ, Louis. O caráter impessoal da experiência. Entre o sensivel e o comunicacional / Bruno Souza Leal, Carlos Camargo Mendonça, César Guimarães (orgs). Belo Horizonte: Autêntica Editora, 2010.

RODRIGUES, José Carlos. "Constantes e variáveis significacionais nos ritos e mitos associados à morte". XIX Encontro Anual da Associação Nacional dos Programas de Pós-Graduação em Comunicação, 2010, PUC-Rio, Rio de Janeiro. Anais eletrônicos.

SILVA, Gislene. Imaginário coletivo: estudos do sensível na teoria do jornalismo. Revista Famecos, Porto Alegre, v.17, $\mathrm{n}^{\circ} 3$, set/dez. 2010, p. 244-252.

SILVA, Gislene. Imaginários de morte, o acontecimento noticioso primordial. Estudos em Jornalismo e Midia, v. 9 n 2, jul/dez. 2012, 462-474.

SILVA, Gislene; VOGEL, Daisi. Imagens de morte na primeira página. In: BERGER, Christa; HENN, Ronaldo; MARROCO, Beatriz (Orgs). Jornalismo e acontecimento: diante da morte. Florianópolis: Insular, v.3, 2012. p. 169-183.

\section{Textos do corpus analisado}

ANTUNES, Elton. Notícias depois da morte: visibilidades e ausências no jornalismo. In: BERGER, Christa; HENN, Ronaldo; MARROCO, Beatriz (Orgs). Jornalismo e acontecimento: diante da morte. Florianópolis: Insular, v.3, 2012. p. 49-69.

BENETTI, Marcia. A apropriação discursiva da morte pelo leitor. In: BERGER, Christa; HENN, Ronaldo; MARROCO, Beatriz (Orgs). Jornalismo e acontecimento: diante da morte. Florianópolis: Insular, v.3, 2012. p. 149-167.

BERGER, Christa. O gênero que mata: memória de punição. In: BERGER, Christa; HENN, Ronaldo; MARROCO, Beatriz (Orgs). Jornalismo e acontecimento: diante da morte. Florianópolis: Insular, v.3, 2012. p. 221-243.

HENN, Ronaldo. Os mortos vivem no twitter: outras camadas da morte como acontecimento. In: BERGER, Christa; HENN, Ronaldo; MARROCO, Beatriz (Orgs). Jornalismo e acontecimento: diante da morte. Florianópolis: Insular, v.3, 2012. p. 111-129. 
Estudos em Jornalismo e Mídia - Vol. 10 NN$^{\circ} 2$ - Julho a Dezembro de 2013

LEAL, Bruno Souza. O realismo em questão: reflexões a partir da morte como acontecimento nas narrativas jornalísticas. In: BERGER, Christa; HENN, Ronaldo; MARROCO, Beatriz (Orgs). Jornalismo e acontecimento: diante da morte. Florianópolis: Insular, v.3, 2012. p. 91-109.

MARROCO, Beatriz. A morte iminente no fait divers. In: BERGER, Christa; HENN, Ronaldo; MARROCO, Beatriz (Orgs). Jornalismo e acontecimento: diante da morte. Florianópolis: Insular, v.3, 2012. p. 185-201.

MEDITSCH, Eduardo. Consentimento para matar: o contexto sociocultural como substrato do acontecimento na cobertura. In: BERGER, Christa; HENN, Ronaldo; MARROCO, Beatriz (Orgs). Jornalismo e acontecimento: diante da morte. Florianópolis: Insular, v.3, 2012. p. 131-147.

PORCELLO, Flávio. Sensacionalismo, espetacularização e visibilidade: as notícias sobre as mortes de Chico Anysio e Millôr Fernandes nos telejornais. In: BERGER, Christa; HENN, Ronaldo; MARROCO, Beatriz (Orgs). Jornalismo e acontecimento: diante da morte. Florianópolis: Insular, v.3, 2012. p. 203-219.

SILVA, Gislene; VOGEL, Daisi. Imagens de morte na primeira página. In: BERGER, Christa; HENN, Ronaldo; MARROCO, Beatriz (Orgs). Jornalismo e acontecimento: diante da morte. Florianópolis: Insular, v.3, 2012. p. 169-183.

TAVARES, Frederico Brandão de Melo. A cotidianidade do morrer na vida noticiosa: ambiguidades de um acontecimento jornalístico diário. In: BERGER, Christa; HENN, Ronaldo; MARROCO, Beatriz (Orgs). Jornalismo e acontecimento: diante da morte. Florianópolis: Insular, v.3, 2012. p. 71-89.

VAZ, Paulo Bernardo. Lições de morte nos jornais. In: BERGER, Christa; HENN, Ronaldo; MARROCO, Beatriz (Orgs). Jornalismo e acontecimento: diante da morte. Florianópolis: Insular, v.3, 2012. p. 21-47.

Este artigo e todo o conteúdo da Estudos em Jornalismo e Mídia estão disponíveis em http://www.periodicos.ufsc.br/index.php/jornalismo/index

Estudos em Jornalismo e Mídia está sob a Licença Creative Commons 